\title{
Infografías científicas en secundaria: complejos de significados multimodales en ensambles compuestos verbales-visuales
}

\author{
High School Science Infographics: Multimodal \\ Meaning Complexes in Composite Image-Language \\ Ensembles
}

\author{
Len Unsworth
}

Australian Catholic University

\section{Resumen}

\begin{abstract}
Desde hace tiempo, la complejidad del discurso científico ha sido identificada como desafiante para muchos estudiantes. Los análisis de la lingüística sistémico funcional sobre tecnicalidad y agregación de significados, que diferencian el discurso científico del cotidiano, han explicado la complejidad lingüística a la que se enfrentan los estudiantes. La complejidad de las imágenes y los ensambles de imagen-lenguaje en el discurso científico no ha sido descrita de manera similar. Dos aspectos de la construcción de significados multimodales no se han teorizado suficientemente para apoyar a las pedagogías de interpretación y creación de visualizaciones en las ciencias: 1) se ha ignorado en gran medida el rol de lo verbal dentro de las representaciones visuales científicas; 2) el análisis de imágenes ha hecho hincapié en las imágenes de estructura simple, por ejemplo narrativas, clasificatorias o analíticas, mientras que las estructuras múltiples en una sola imagen son un recurso frecuente y significativo en las ciencias. Este artículo presenta un marco en el que se describe el codespliegue de la imagen y la palabra para construir ensambles de estructura múltiple imagen-lenguaje en los libros de texto de ciencias para secundaria. Usando este marco, se describen dos investigaciones: (1) la variación entre las infografías de los libros de texto en la coarticulación imagen-lenguaje, que representa complejos de significados de fenómenos como la mitosis; (2) la relación entre la coarticulación de los recursos imagen-lenguaje y el nivel de logro en las infografías construidas por los estudiantes de secundaria. Se establecen implicancias para extender la investigación transdisciplinaria en semiótica educativa y en educación científica, y para pedagogías que promuevan el desarrollo de la literacidad disciplinar multimodal en ciencia para la escuela secundaria.
\end{abstract}

Palabras clave: literacidad en ciencias, infografías, multimodalidad, lingüística sistémico funcional, libros de texto

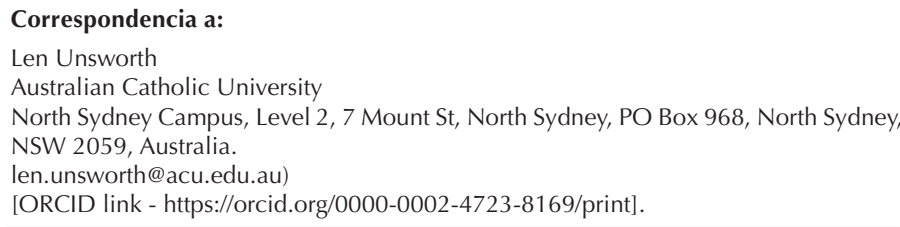

(C) 2021 PEL, http://www.pensamientoeducativo.org - http://www.pel.cl 


\begin{abstract}
The complexity of science discourse has long been recognized as challenging for many students. Systemic functional linguistic accounts of technicality and meaning aggregation, differentiating scientific and everyday discourse, have explicated the linguistic complexity confronting students. The complexity of images and image-language ensembles in science discourse has not been similarly delineated. Two aspects of multimodal meaning-making have not been sufficiently theorized to support pedagogies of visualization interpretation and creation in science: (1) the role of the verbiage within scientific visualizations has been largely ignored; (2) image analysis has emphasized single-structure images, e.g. narrative or classificational or analytical, whereas multiple structures in a single image is a frequent and significant resource in science. This paper outlines a framework describing the co-deployment of image and verbiage to construct multi-structure image-language ensembles in high school science textbooks. Using this framework two investigations are described: (1) variation among textbook infographics in image-language co-articulation representing meaning complexes of phenomena such as mitosis; (2) the relationship between co-articulation of image-language resources and achievement level in infographics constructed by senior high school students. Implications are drawn for extending transdisciplinary research in educational semiotics and science education and for pedagogies of multimodal disciplinary literacy development in high school science.
\end{abstract}

Keywords: science literacy, infographics, multimodality, systemic functional linguistics, textbooks

\title{
Infografías científicas en secundaria: complejos de significados multimodales en ensambles compuestos verbales-visuales
}

Durante mucho tiempo, se ha reconocido la complejidad del discurso distintivamente científico como un desafío para el aprendizaje de los estudiantes, en especial aquellos de bajo nivel socioeconómico o cuya primera lengua no es el idioma oficial de enseñanza (Nunes et al., 2017; Teese, 2013). Ha habido un impresionante número de investigaciones sobre la complejidad del discurso científico y su accesibilidad para los estudiantes. Es posible que la investigación más importante en términos educacionales provenga de la lingüística sistémico funcional (LSF) a partir de los trabajos sobre lenguaje de Halliday (Halliday \& Martin, 1993), Martin (Martin, 2017; Martin \& Veel, 1998) y Lemke (1990, 2004). Desde el punto de vista de la negociación del discurso científico por parte de los estudiantes, resulta significativa la descripción de la construcción lingüística de la tecnicalidad y los recursos textuales para la agregación de significado, que explican cómo esto distingue al discurso científico del cotidiano en relación con los fenómenos e identifica la naturaleza lingüística de la complejidad a la que se enfrentan los estudiantes (Martin, 2020)

La complejidad de las imágenes y de los ensambles compuestos verbales-visuales en el discurso científico a la que se enfrentan los estudiantes de ciencias todavía no ha sido descrita en profundidad de igual forma. Los estudios fundamentales sobre los recursos de construcción de significados de imágenes provenientes o relacionados con la tradición de la lingüística sistémica funcional que han incluido imágenes recogidas de las ciencias han prestado poca atención al lenguaje verbal que usualmente ocurre en tales imágenes. Las imágenes científicas en estos estudios no han sido analizadas en el contexto del discurso propio de la ciencia, ni se ha abordado la 
complejidad ideacional relativa de tales imágenes (Bateman, 2008; Höllerer et al., 2019; Kress \& van Leeuwen, 2021). En su obra seminal sobre la gramática del diseño visual, Kress y van Leeuwen (2006) se focalizaron en las imágenes estructurales únicas (Doran, 2019). Kress y van Leeuwen (2006) describen la representación de significados ideacionales en términos de estructuras narrativas (que construyen actividad), estructuras de clasificación (que construyen relaciones de clase-subclase), estructuras analíticas (que principalmente construyen relacionales de composición), y estructuras simbólicas. No queda claro en el enfoque de Kress y van Leeuwen si las imágenes pueden contener y conceder el mismo estatus a más de una de estas estructuras (Doran, 2019). Kress y van Leeuwen (2006) sí indican que las líneas de tiempo parecen ocupar una posición intermedia entre lo narrativo y lo analítico, y que las genealogías y los árboles filogenéticos y gráficos pueden borrar las barreras entre lo estático y lo dinámico (Kress \& van Leeuwen, 2006). También sugieren que la incrustación puede ocurrir en diagramas y proporcionan un ejemplo en el que la estructura narrativa está embebida dentro de una estructura analítica. No obstante, el principal énfasis de su trabajo se sitúa en las imágenes de estructura única. Esto parece haber influenciado a muchas publicaciones posteriores con orientación pedagógica que utilizaron su enfoque, que también limitan su análisis a imágenes de estructura única (Callow, 2013; Callow, 1999; de Silva Joyce \& Gaudin, 2007; Knain, 2015). Sin embargo, el uso de múltiples estructuras en una sola imagen es un recurso frecuente e importante en la investigación y educación científica, lo que contribuye sustancialmente a la complejidad del discurso científico multimodal y que los estudiantes necesitan sortear a medida que avanzan en la secundaria. La naturaleza de la complejidad de las visualizaciones y del lenguaje verbal incorporado dentro de estas ha sido analizada en muy pocos de los numerosos estudios semióticos de corte sistémico-funcionales sobre el discurso científico escolar (Doran, 2017, 2019; Martin, 2020; Unsworth, 2020; Unsworth \& Cleirigh, 2009a, 2009b). Doran y Martin describieron la representación de fenómenos en estos ensambles multimodales en los textos de ciencias desde la perspectiva del campo, que es un recurso para construir fenómenos como actividades en paralelo a las taxonomías de elementos involucrados en estas secuencias (organizadas tanto por clasificación como composición), en conjunto con propiedades asociadas (Doran \& Martin, 2021). Señalaron que estos ensambles multimodales, por lo general, representan de forma simultánea dos o más aspectos del campo, y que las imágenes combinadas con anotaciones y bloques de texto interpolados agregan significado en representaciones sinópticas altamente condensadas, lo que contribuye a la naturaleza de la complejidad que los estudiantes tienen que afrontar (Doran, 2019; Martin, 2020).

En este trabajo, se expone la investigación actual basada en estos estudios para elaborar un marco que describa las opciones para la coarticulación de la imagen y el lenguaje verbal, y cómo esto agrega significados ideacionales que construyen el campo en las infografías que los estudiantes de ciencias de secundaria necesitan interpretar y crear (Martin \& Unsworth, en preparación; Martin et al., en prensa). El marco que se presenta se utiliza, en primer lugar, para investigar la variación entre las infografías de los libros de texto en su despliegue respecto de la coarticulación imagen-lenguaje verbal dentro de la representación multimodal de fenómenos científicos complejos, tales como la mitosis en la replicación del ADN celular. En segundo lugar, se revisan las infografías construidas por estudiantes de secundaria en respuesta a las preguntas de un examen para investigar la relación entre la coarticulación de los recursos de imagen-lenguaje y la calidad de sus respuestas.

\section{Marco teórico}

\section{Infografías científicas escolares}

Por cerca de dos décadas, la investigación ha documentado el predominio de la imagen como locus retórico del "oficio" y de los libros de textos de ciencias (Bateman, 2008; Bezemer \& Kress, 2010; Danielsson \& Selander, 2016; Kress, 2005; Peterson, 2016), al punto de que, en algunos casos, el texto tradicional ha sido suprimido a 
favor de representaciones basadas en imágenes que pueden incluir anotaciones, bloques de textos interpolados y una leyenda (Danielsson \& Selander, 2016; Martin \& Rose, 2012). Tales ensambles multimodales también se encuentran cada día más en la difusión de las ciencias en sitios web y en la prensa, así como en folletos y otras publicaciones del gobierno y autoridades semigubernamentales (Polman \& Gebre, 2015), lo que ha inspirado a los educadores científicos a adoptar la creación de infografías como experiencia de aprendizaje para los estudiantes (Gebre \& Polman, 2016; Ozdamli \& Ozdal, 2018; Walsh \& McGowan, 2017). Sin embargo, durante varios años, el uso de representaciones multimodales de imagen y lenguaje verbal creadas por los estudiantes ha sido cada vez más promovido en la investigación como un aspecto fundamental de la indagación estudiantil para mejorar el aprendizaje de las ciencias, lo que ha ocurrido de forma predominante en la escuela primaria (básica) y el primer ciclo de secundaria (McDermott \& Hand, 2013; Tytler, Prain, \& Hubber, 2018). No obstante, este tipo de combinación de varias formas de visualizaciones y lenguaje verbal con prominencia de imágenes también ejemplifica la forma prevista de las respuestas de los estudiantes a muchas de las preguntas de respuesta breve en los exámenes de ciencias del último año de secundaria en muchos países como el Reino Unido, Singapur, Australia y Nueva Zelanda. Pese a la prominencia de las representaciones infográficas en los libros de textos y otros materiales de aprendizaje, y del uso de representaciones multimodales que se insta a los estudiantes a construir en torno a la coarticulación eficaz de imagen y lenguaje verbal, la investigación ha prestado poca atención a cómo estas imágenes y sus componentes lingüísticos se combinan en la construcción de significado para servir de base al desarrollo del aprendizaje crítico de los estudiantes para leer esas representaciones, así como al desarrollo de su creación real de infografías científicas (McDermott \& Hand, 2013, 2016; Polman \& Gebre, 2015).

\section{Despliegue de imágenes y lenguaje en el diseño de infografías}

La investigación semiótica reciente y en curso que analiza las infografías en los libros de texto científicos de secundaria y los sitios web relacionados ha comenzado a documentar el repertorio de opciones para las maneras en que las imágenes y el lenguaje verbal se despliegan en estas representaciones multimodales (Martin et al., en prensa; Unsworth, 2020). El componente de imagen de las infografías puede consistir en uno o más de los diversos tipos de imágenes, tales como fotografías, ilustraciones, diagramas, gráficos, etc., o una combinación de los distintos tipos de imágenes. La figura 1 muestra ejemplos de infografías de libros de textos científicos de secundaria que representan las partes y el funcionamiento del oído (Bennett, 2017, p. 108) y las fases de la mitosis en la réplica del ADN celular (Chidrawi et al., 2013, p.19). 


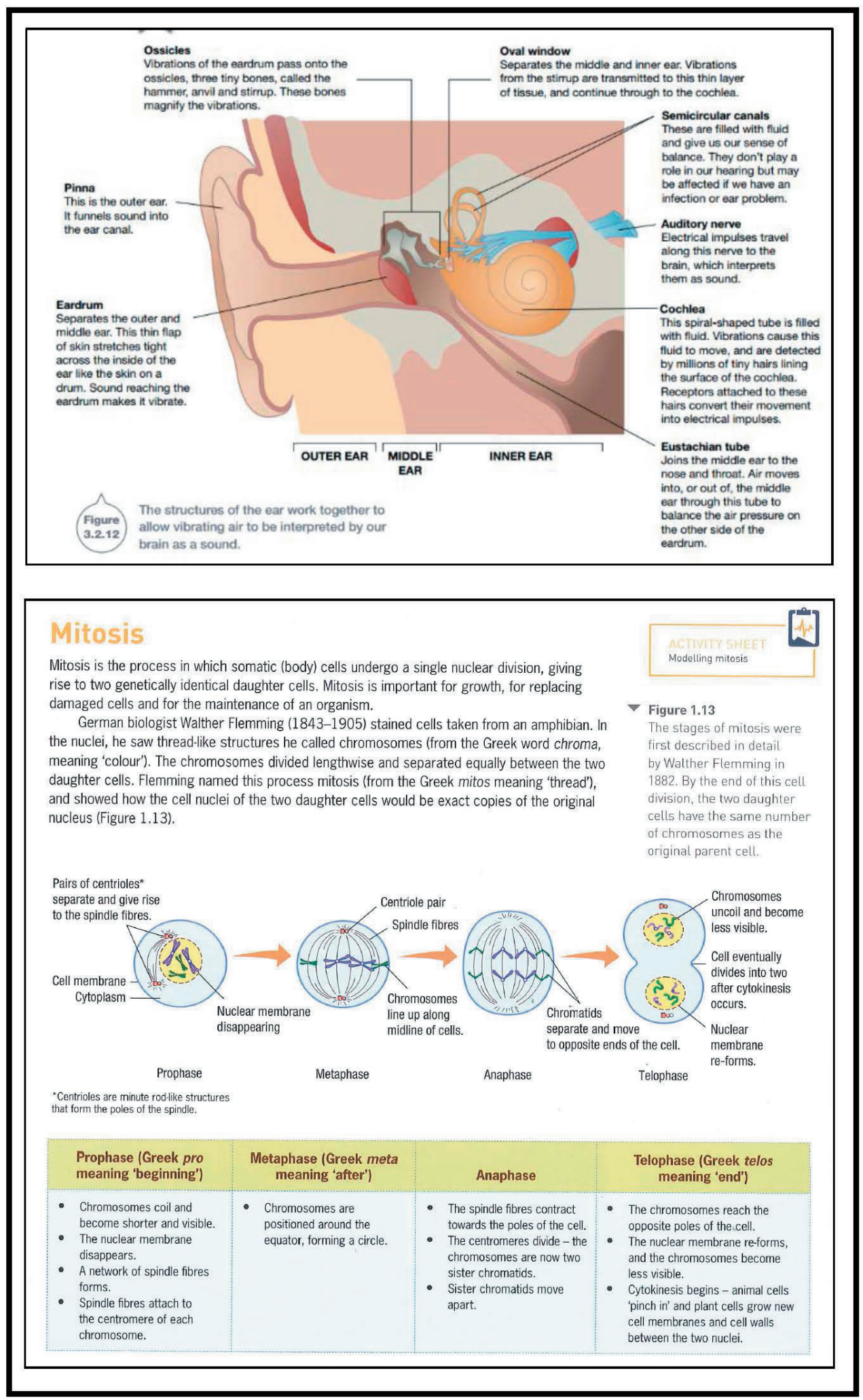

Figura 1. Infografias de los libros de textos de ciencias

Fuente: Rickard, G. (2017) \& Chidrawi et al. (2013). 
Los componentes verbales pueden incluir anotaciones o cotexto que pueden consistir en una leyenda y uno o más bloques de textos interpolados. En la infografía del efecto invernadero de los gases (figura 3) se pueden ver ejemplos de bloques de textos interpolados. El cotexto como leyenda o el bloque de texto interpolado se relaciona con la imagen como un todo, mientras que las anotaciones se relacionan con partes específicas de la imagen. En la figura 1, las anotaciones se refieren a partes puntuales de la imagen, como se especifica en las líneas de conexión. Las leyendas (ubicadas debajo de la imagen del oído y en la esquina superior derecha del diagrama de mitosis) se refieren a la imagen como un todo.

En la figura 2 se muestra una representación simplificada de opciones para el despliegue de imágenes y lenguaje verbal en las infografías y para la agregación del campo de construcción de significados ideacionales.
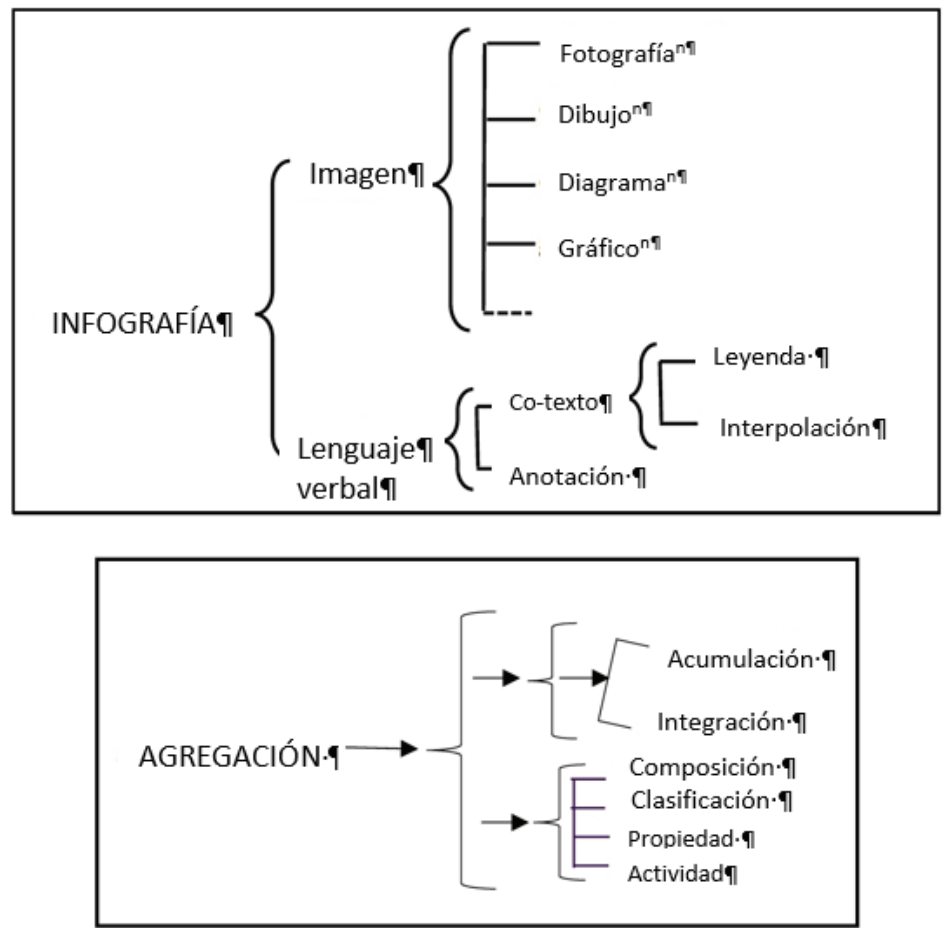

Figura 2. Infografias y agregación

Fuente: Elaboración propia.

El corchete a la izquierda de 'infografía' en la figura 2 indica que las infografías se componen de al menos una imagen además de lenguaje verbal. El corchete izquierdo de 'imagen', en conjunto con los paréntesis cuadrados, indica que el componente de imagen puede consistir en solo uno de los tipos de imágenes o en una combinación de un número indefinido de tipos de imágenes. El corchete la izquierda de 'verbal', junto con los paréntesis cuadrados, indica que el componente verbal puede consistir en cotextos, anotaciones o ambos, y de igual forma el cotexto puede consistir en una leyenda o texto interpolado, o ambos. Aquí intepretaremos la infografía desde la perspectiva de su representación de significados que construyen campo, siguiendo a Doran y Martin (2021). Como ya se ha indicado, las infografías pueden construir una o más dimensiones de campo, lo que incluye actividad, clasificación y composición de entidades y propiedades de actividad o entidades, y estas se pueden representar solo en imágenes, solo con lenguaje verbal o en una combinación de ambos. Parte de la complejidad de algunas infografías es su representación de dos o más de estas dimensiones de campo de forma simultánea y con el mismo estatus. Nos referimos a este aspecto de complejidad como agregación: el grado en el que la actividad, la clasificación, la composición y las propiedades se combinan en una infografía. 


\section{Agregación mediante acumulación e integración}

El sistema para la agregación en la figura 2 media las opciones para la inclusión del campo que construye tecnicalidad (composición, clasificación, actividad y propiedad), con dos opciones para combinar estos significados en infografías: (1) acumulación e (2) integración.

Acumulación se refiere a la agregación de distintos tipos de significado (composición, clasificación, actividad y propiedad) a partir de dos o más macrogrupos, cada uno de los cuales consiste en una imagen + /- anotaciones y +/- texto interpolado. La integración se refiere a la agregación dentro de un macrogrupo a través de la (a) incorporación de dos o más dimensiones de actividad, clasificación, composición y propiedad dentro de una imagen; (b) representación de distintas dimensiones de significado que construye campo en una imagen y en las anotaciones, y (c) descripción de la actividad como una representación verbal de la entidad y una representación visual de un proceso de acción. La agregación en las infografías puede incluir ya sea una o ambas de las opciones de acumulación e integración en mayor o menor medida, por lo que en la figura 2 estas opciones aparecen representadas como una clina.

La agregación mediante la acumulación se ejemplifica en la figura 3, en las infografías que representan el efecto invernadero (Lofts \& Evergreen, 2015, p. 228) y la conducción de impulsos celulares nerviosos en el axón (Huxley \& Walter, 2019, p.260).

En la representación del efecto invernadero en la figura 3 ambos macrogrupos de imágenes representan la actividad de la energía irradiada desde el Sol a la Tierra y la reverberación de esta radiación desde la superficie de la Tierra solamente por medio de las imágenes. La imagen del lado derecho también incluye una composición del continente que muestra las entidades de una casa, una fábrica, un edificio, un auto y ganado con alguna actividad en forma de emisiones de las primeras cuatro entidades. Sin embargo, es la combinación de las dos imágenes la que agrega la clasificación comparativa del entorno antes y después de la introducción del desarrollo agrario e industrial. La agregación de significado entre los dos macrogrupos también puede ser vista en la infografía sobre la conducción de los impulsos nerviosos en el axón en la figura 3. El macrogrupo de imágenes del axón en la parte superior muestra los significados composicionales fundamentales. El soma es una porción expandida del citoplasma que contiene el núcleo (este se muestra como un círculo más oscuro, pero no se identifica). La sección alargada que se extiende hacia la derecha es el axón, que es la principal compuerta para la conducción de impulsos nerviosos desde el terminal del axón. Se muestran otros componentes de la neurona, pero no se indican sus nombres. El segundo macrogrupo consiste en una línea de acción delgada y negra, bajo la cual hay tres bandas horizontales paralelas, cada una con una anotación alineada que explica la actividad. Las filas, leídas de forma descendente, indican la despolarización progresiva de la repolarización de las secciones posteriores del axón como medio para conducir el impulso nervioso.

Los libros de textos de ciencias de secundaria están llenos de infografías que agregan significado mediante la representación de dos o más de las dimensiones de campo de la actividad, de la composición de la clasificación y de la propiedad dentro del mismo macrogrupo. Esto puede ocurrir dentro de una misma representación visual. Un área donde este tipo de agregación de significado es esencial para la construcción representacional de fenómenos corresponde a los procesos biológicos, tales como la mitosis que se representa en la figura 1 . Esta infografía incluye un macrogrupo de diagramas que consiste en cuatro microgrupos de imágenes redondas en conjunto con una serie de microgrupos verbales como anotaciones (Martin \& Unsworth, en preparación; Martin, Unsworth \& Rose, en prensa). Cada uno de los microgrupos describe entidades composicionales dentro de la célula en distintas fases de la mitosis y se vinculan por medio de flechas que representan la progresión de una fase a la siguiente. La descripción del cambio de las relaciones de composición en la célula está interconectada con la descripción de la actividad de transformación de la célula, por medio de la profase, la metafase, la anafase y la telofase. Esta actividad progresiva se describe en parte con las flechas entre las imágenes sucesivas de la célula. 

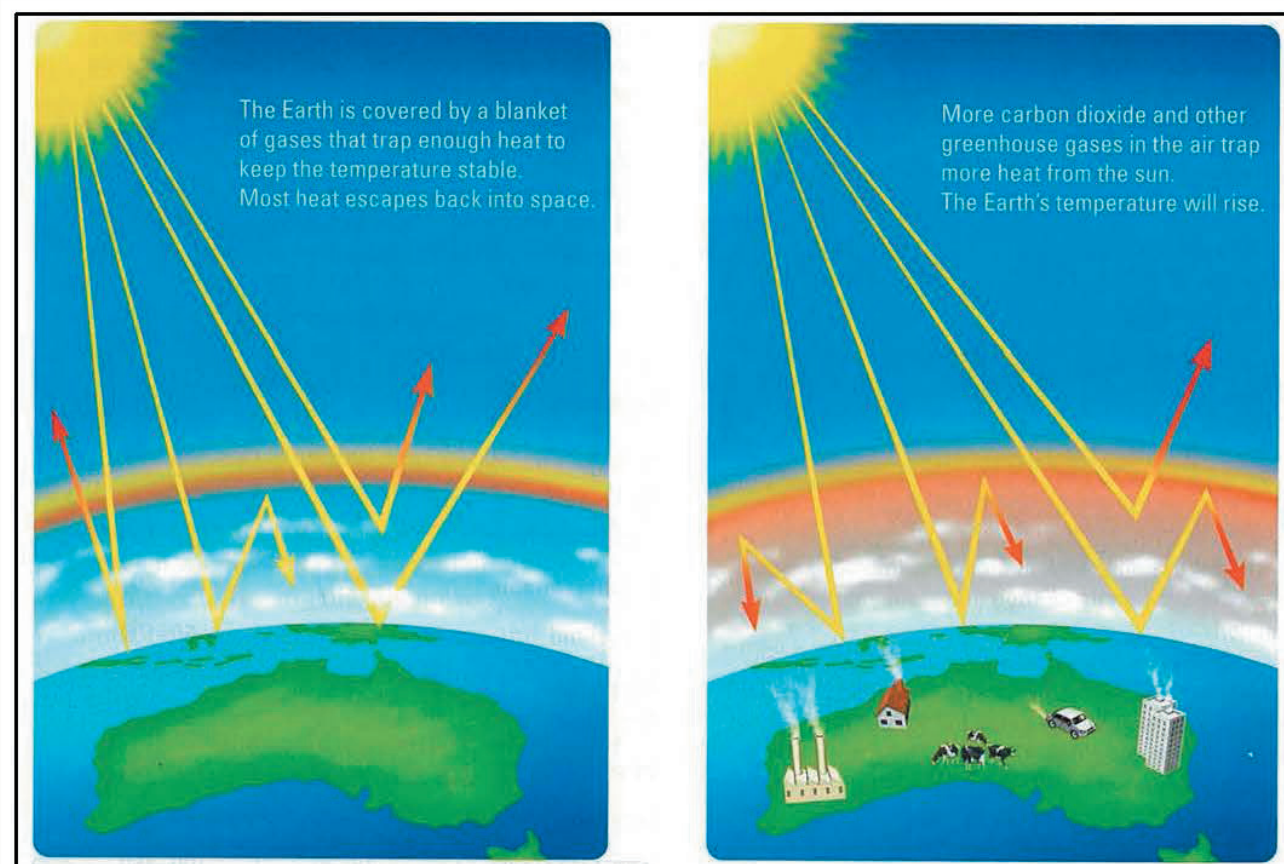

Greenhouse gases and the enhanced greenhouse effect

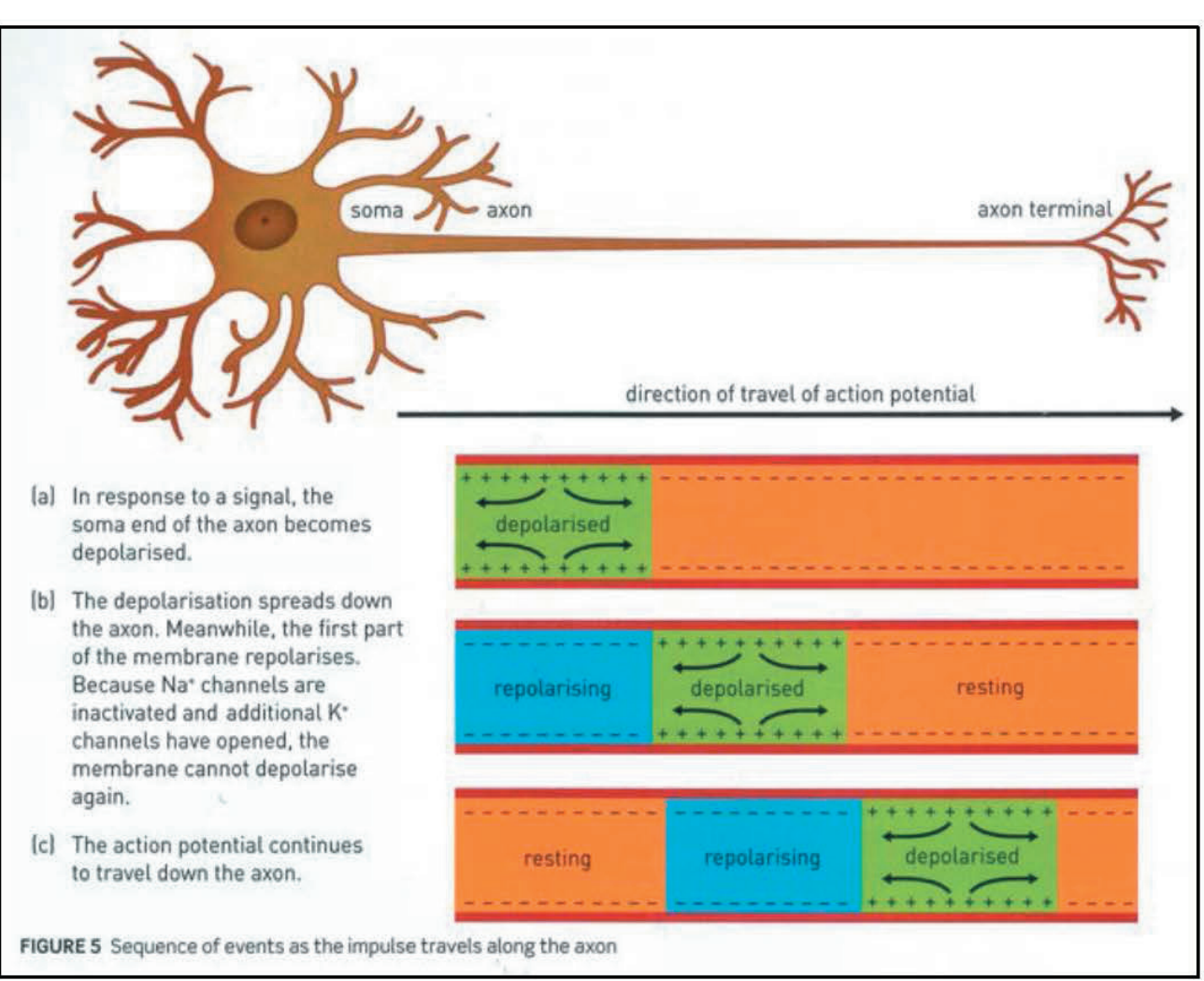

Figura 3. Agregación por medio de acumulación

Fuente: Lofts \& Evergreen (2015) y Huxley \& Walter (2019). 
Sin embargo, cada imagen de la célula también muestra los componentes distintivos de esta en esa fase. Por ejemplo, desde la profase hasta la metafase, la membrana nuclear y el núcleo definido en la profase desaparecen; los cromosomas son reconfigurados para que se alineen alrededor del centro de la célula; los centríolos cambian la posición de los polos de la célula, y las fibras del huso pasan de acumularse alrededor de la membrana nuclear a irradiar desde los centríolos en ambos polos de la célula. Lo anterior muestra que, mientras que la actividad se puede representar visualmente con vectores (Kress \& van Leeuwen, 2006), también se puede inferir de imágenes similares posteriores, cuando los elementos aparezcan o desaparezcan, o cuando vuelvan a aparecer en una forma distinta (Painter, Martin and Unsworth, 2013).

Una segunda forma en la que la agregación puede ocurrir por medio de la integración es cuando uno o más aspectos de la construcción de campo son expresados por la imagen y uno o más aspectos distintos de la construcción de campo son expresados por lo verbal. En la infografía sobre el oído en la figura 1, la imagen representa solo la composición del oído. No hay vectores (líneas de acción) u otra representación visual de la actividad que indique el funcionamiento del oído. Los títulos destacados de las anotaciones mencionan los componentes del oído. La parte principal de la anotación puede extender la taxonomía de composición al nombrar los subcomponentes o al indicar la función del componente. Por ejemplo, los osículos auditivos están compuestos por el martillo, el yunque y el estribo, y los canales semicirculares 'nos dan la sensación de equilibrio'. No obstante, las anotaciones también pueden realizar la actividad, como en 'Esto (el oído menor) encauza el sonido por el canal auditivo' y 'El sonido que llega al tímpano lo hace vibrar'. Las realizaciones de la actividad en las anotaciones pueden ser figuras (cláusulas), tales como 'Esto (el oído menor) encauza el sonido por el canal auditivo' o 'El sonido que llega al tímpano lo hace vibrar'. Sin embargo, la actividad también se puede realizar por medio de una entidad de actividad (en la forma de un grupo nominal) tales como 'Vibraciones del tímpano' en la anotación de los osículos, que es una condensación de la construcción de esta actividad como una figura o cláusula en la anotación del tímpano ('El sonido que llega al tímpano lo hace vibrar'). Las anotaciones también construyen propiedades, tales como la tirantez de la piel sobre el tímpano o la ventana oval como una capa 'delgada' de tejido. La infografía sobre el oído no incluye una clasificación. Las opciones para la designación verbal de la clasificación en las anotaciones incluyen especificar el superordinado, nombrando los subtipos y los criterios de categorización. Además de la construcción de estos aspectos de campo, el lenguaje verbal también puede realizar relaciones causales. En la figura 1, por ejemplo, en la anotación sobre la cóclea, 'Las vibraciones causan que este fluido se mueva...'

La tercera forma en que la agregación ocurre por medio de la integración es por medio de la construcción de significados en la intersección de imagen y lenguaje verbal. La limitación de la revista en cuanto a los números de figuras no permite que esto se ilustre. Sin embargo, se entrega un claro ejemplo en la infografía de la fotosíntesis (Huxley \& Walter, 2019, p. 113). Esta representación muestra la realización intermodal de la actividad, con eventos de absorción de dióxido de carbono y descarga de oxígeno realizados de forma visual por medio de flechas cafés y azules respectivamente, y una de las entidades que participan (la hoja) también realizada visualmente, mientras que otras entidades que participan (dióxido de carbono y oxígeno) se realizan mediante lenguaje verbal.

\section{Método}

Este estudio cualitativo adoptó un enfoque de análisis de discurso multimodal para investigar, en primer lugar, el alcance relativo en el que se representa la tecnicalidad de la mitosis en las infografías de los libros de textos del primer ciclo de secundaria y la naturaleza de la coarticulación de la imagen y el lenguaje verbal en esta 
representación y, en segundo lugar, cómo esta coarticulación de la imagen-lenguaje verbal se relaciona con las representaciones de calidad de estudiantes sobre la tecnicalidad de un enlace iónico en las respuestas infográficas a una pregunta de examen. Se abordan las siguientes preguntas de investigación:

1. ¿Cómo puede utilizarse un marco para la coarticulación de imagen y lenguaje verbal en la agregación de significado ideacional para evaluar la complejidad y accesibilidad relativas de las infografías científicas de secundaria?

2. ¿Cuál es la calidad de las infografías científicas construidas por los estudiantes en relación con su coarticulación de los recursos de imagen y lenguaje verbal?

\section{Corpus}

El corpus de libros de texto está conformado por ocho libros de secundaria que se utilizan habitualmente en Australia para las clases de biología de $11^{\circ}$ y $12^{\circ}$ grado (Armstrong et al., 2019; Borger, 2015; Chidrawi et al., 2013; Huxley \& Walter, 2019; Kinnear, 2016; Linstead et al., 2012; Lofts \& Evergreen, 2015; Silvester, 2016). Las infografías sobre la mitosis fueron seleccionadas de cada uno de estos textos. Para un análisis comparativo detallado se utilizaron los cuatro textos de $10^{\circ}$ grado.

Las infografías construidas por los estudiantes se seleccionaron de un corpus de veinte respuestas de estudiantes de química de $11^{\circ}$ grado, quienes contestaron a la siguiente pregunta de examen relacionada con los enlaces iónicos:

Cuando un investigador añade $50 \mathrm{~g}$ de nitrato de sodio sólido (NaNO3, una sal iónica) a $100 \mathrm{ml}$

de agua a temperatura ambiente, el nitrato de sodio se disuelve fácilmente. Explica cómo se produce esto en relación con la unión de partículas (utiliza un diagrama para apoyar tu explicación).

Las respuestas de los estudiantes fueron calificadas por el docente en una escala de uno a cinco. Para la comparación se seleccionaron una respuesta que obtuvo cinco puntos y otra que obtuvo dos puntos.

\section{Análisis de datos}

Se analizaron las infografías sobre la mitosis de los ocho libros de texto del corpus para determinar los componentes de la célula y cada etapa (evento separado) de la actividad de la mitosis representados en las imágenes o el lenguaje de cada infografía (Unsworth, 2020). Luego, se recopilaron todos los significados ideacionales de las imágenes y el lenguaje verbal en las ocho infografías que presentan los componentes de la célula y la actividad de la mitosis con el fin de elaborar un mapa exhaustivo de las relaciones de composición y la actividad construidas en las ocho infografías en conjunto. El mapa, que incluía todos los componentes de la célula representados en los textos del corpus, contenía: célula (paredes celulares, citoplasma, membrana plasmática); núcleo (nucléolo, membrana nuclear, cromosomas (cromátidas, centrómero), ADN (cromatina), huso mitótico (centríolos, microtúbulos/fibras)). El mapa compuesto de la actividad durante la mitosis en los textos del corpus incluyó: interfase (los cromosomas se replican); profase (los cromosomas se condensan/se hacen visibles, el nucléolo desaparece, la membrana nuclear desaparece, los pares de centríolos se separan, los microtúbulos/fibras se extienden desde los centríolos, las fibras del huso se unen al centrómero, se forma una red de fibras del huso); metafase (los cromosomas se alinean a lo largo del ecuador de la célula); anafase (las fibras del huso/microtúbulos se contraen, cada centrómero se divide, las cromátidas se separan, las cromátidas se desplazan a los extremos opuestos de la célula); telofase (los cromosomas se desenrollan y se vuelven menos visibles, la membrana nuclear se vuelve a formar, las fibras del huso desaparecen); citocinesis (el citoplasma se divide, se forma una nueva membrana celular, se crean dos células hijas). 
En el siguiente paso, para cada uno de los cuatro textos de $10^{\circ}$ año, el grado de correspondencia de la representación de los componentes de la célula y el de correspondencia de la actividad en etapas (eventos separados) representados en las imágenes fueron mapeados en relación con los compuestos para la composición y la actividad. Se utilizó un procedimiento similar para mapear la representación de los componentes y de la actividad en el lenguaje verbal de cada texto de $10^{\circ}$ grado (combinando los resultados del lenguaje verbal como texto interpolado, anotación y leyenda).

Se compararon las respuestas infográficas construidas por los estudiantes que contestan a la pregunta del examen sobre el enlace iónico en términos de grado y eficacia del despliegue de las opciones para el uso de lo verbal y de lo visual en la representación y agregación del campo de construcción del significado ideacional en las infografías, como se resume en la figura 2. El análisis comparativo consideró el uso relativo de la acumulación y de la integración en la agregación de significado, incluida la selección relacionada del tipo y función de las imágenes, y la naturaleza y el grado del uso de las anotaciones y los bloques de texto, así como la coarticulación de imagen y lenguaje verbal en la combinación y la condensación del significado.

\section{Resultados}

\section{Complejidad y accesibilidad de las infografías sobre la mitosis de los libros}

\section{de texto de $10^{\circ}$ grado}

Tres de los cuatro libros de texto de $10^{\circ}$ grado se basan por completo en imágenes anotadas y leyendas de sus representaciones infográficas para explicar la mitosis (Chidrawi et al., 2013; Lofts, 2015; Silvester, 2016). Cada uno de ellos incluye una cantidad muy reducida de cuerpo de texto tradicional que no explica el proceso, por lo que solo se analizaron las infografías. El cuarto libro de texto de $10^{\circ}$ grado $(\mathrm{P})$ es el único cuya infografía de la mitosis va acompañada de un cuerpo de texto que constituye una explicación del proceso de la mitosis (Linstead et al., 2012). Este análisis determinó para cada uno de los textos de $10^{\circ}$ año el grado en el que se representa la composición y la actividad de las explicaciones compuestas, y cómo fue la distribución entre los modos visual y verbal. Los resultados de la representación de los componentes de la célula y la actividad de la mitosis se muestran en la tabla 1.

Tabla 1

Resumen de la distribución de la representación de los componentes de la célula y la actividad de la mitosis en la imagen y el lenguaje verbal.

\begin{tabular}{ccccc} 
Infografía de los libros de texto & $\mathrm{O}$ & $\mathrm{N}$ & $\mathrm{J}$ \\
\hline Imagen o lenguaje verbal & & Representación de la composición celular & 11 \\
\hline Imagen + lenguaje verbal & 7 & 12 & 5 & 11 \\
\hline Solo lenguaje verbal & 1 & 11 & 0 & 10 \\
\hline Solo imagen & 2 & 1 & 6 & 1 \\
\hline Imagen o lenguaje verbal & 11 & 0 & 11 & 15 \\
\hline Imagen + lenguaje verbal & 8 & 16 & 3 & 9 \\
\hline Solo lenguaje verbal & 1 & 11 & 2 & 1 \\
\hline Solo imagen & 2 & 4 & 6 & 5 \\
\hline
\end{tabular}

Fuente: Elaboración propia. 
En la tabla 1 se muestra, en la primera fila de las representaciones de la composición celular, el número de relaciones de composición construidas con imagen o lenguaje verbal; la segunda fila muestra el número de representaciones construidas con lenguaje verbal e imagen en conjunto, seguido de las construidas solo con lenguaje verbal y luego solo con imagen. Aunque todos los textos incluyen casi el mismo número de componentes de la célula, es evidente que ambos textos $\mathrm{N}$ y $\mathrm{P}$ los representan y nombran a casi todos, como se indica en la segunda fila. La construcción intermodal de la composición corrobora que hay relaciones taxonómicas más profundas en los textos $\mathrm{N}$ y $\mathrm{P}$ en comparación con los textos $\mathrm{O}$ y J. Los componentes en los primeros también se identifican por medio de lenguaje verbal, mientras que, específicamente en el texto $\mathrm{J}$, al menos la mitad de los componentes solo se representan con imágenes. Como no hay un cuerpo de texto explicativo de la mitosis, la interpretación y el aprendizaje del texto J por parte de los estudiantes depende en gran medida del incrementamiento de información que proporciona el docente o los textos alternativos.

La construcción más completa y explícita de la actividad se produce en las infografías $\mathrm{N}$ y $\mathrm{P}$, como se muestra en la primera y segunda fila de la tabla 1, en la sección sobre la representación de la actividad en la mitosis. En estos textos, la única actividad que se construye únicamente a partir de lo verbal es 'las fibras del huso desaparecen'. Como se muestra en la segunda fila, la imagen y el lenguaje verbal concurren en gran parte de la construcción de la actividad. Lo demás se construye principalmente por medio del lenguaje verbal. Si bien la infografía $\mathrm{O}$ muestra menos compromiso con la actividad que los textos $\mathrm{N}$ y $\mathrm{P}$, tanto en términos visuales y del lenguaje verbal, hay bastante concurrencia en lo que se compromete en el texto $\mathrm{O}$, como se muestra en la segunda fila. La infografía J tiene el mismo nivel general de compromiso con la actividad que el texto O. Sin embargo, tiene poca concurrencia y una proporción significativa de la actividad tiene un compromiso solo en las imágenes. El patrón de representación de la composición y la actividad es muy similar en el texto J.

En resumen, los cuatro textos representan profundidades similares de las relaciones taxonómicas de composición, pero los textos $\mathrm{N}$ y $\mathrm{P}$ también nombran casi todos los componentes representados. Los textos $\mathrm{N}$ y $\mathrm{P}$ son también los que ofrecen una representación más amplia de la actividad, con un alto grado de concurrencia entre la representación visual y la realización verbal de la actividad. El texto J se basa más en la representación visual, únicamente para las relaciones de composición y la actividad y, por lo tanto, su uso depende en gran medida del incrementamiento mediante la explicación del docente y alguna forma de anotación adicional o materiales de aprendizaje alternativos.

\section{Despliegue de los recursos infográficos en las respuestas con alta y baja puntuación de}

\section{los estudiantes}

Se comparará la respuesta de un estudiante con mayor rendimiento, Amri, con la de un estudiante con menor rendimiento, Sim, para mostrar cómo la respuesta de Amri despliega de mejor manera una gama más amplia de opciones para agregar significado en las infografías. Considerando los errores conceptuales en la respuesta de Sim, la atención se centrará en la elección más adecuada de diagramas por parte de Amri, así como en el uso más amplio y eficaz de la anotación con fines múltiples, y la cohesión entre los bloques de texto interpolados y los dos macrogrupos de diagramas. Las respuestas infográficas proporcionadas por Amri y Sim se muestran en la figura 4. 

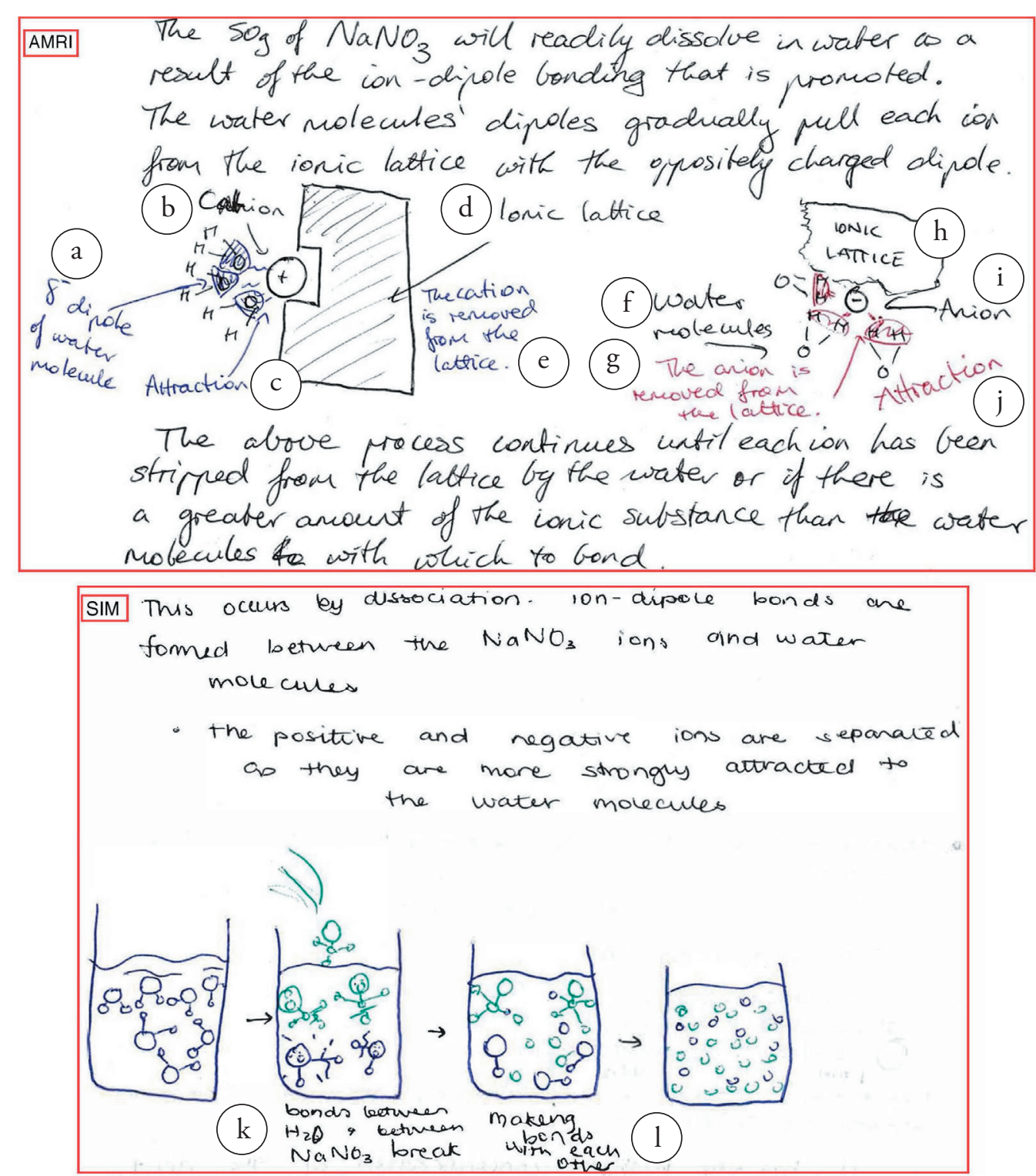

\section{* Traducción del cuadro}

\section{AMRI:}

Parte superior: Los $50 \mathrm{~g}$ de NaNo3 se disuelven fácilmente en agua como resultado del enlace ion-dipolo que se está realizando. Los dipolos de las moléculas de agua gradualmente expulsan cada ion de la red iónica con un dipolo de carga opuesta

Figura de la izquierda: a) 8 dipolos de moléculas de agua, b) Catión, c) Atracción, d) Red iónica,

e) El catión es expulsado de la red iónica.

Figura de la derecha: f) Moléculas de agua, g) El anión es expulsado de la red iónica, h) Red iónica, i) Anión, j) Atracción. Parte inferior: El proceso anterior sigue hasta que cada ion ha sido liberado de la red cristalina por el agua o si existe una mayor cantidad de sustancia iónica que de moléculas de agua a los cuales enlazarse.

SIM:

Parte superior: Esto ocurre por disociación. Se forman enlaces ion-dipolo entre los iones NaNo3 y las moléculas de agua. Los iones positivos y negativos se separan debido a que son atraídos más fuertemente por las moléculas de agua. Figura: k) Los enlaces entre $\mathrm{H}_{2} \mathrm{O}$ y entre $\mathrm{NaNo}_{3}$ se rompen, l) formando enlaces entre sí.]

Figura 4. Explicaciones del agua como solvente para el nitrato de sodio con calificación alta y baja*

Fuente: En el texto principal se utilizan seudónimos, por lo tanto no se citará la fuente para respetar el acuerdo de ética de la investigación. 
La mención por parte de ambos estudiantes del enlace iónico-dipolar sugiere que comprenden que cuando un compuesto iónico como el cloruro de sodio o el nitrato de sodio se ańade al agua los extremos positivos de las moléculas de agua son atraídos por los iones de cloruro o nitrato cargados negativamente y los extremos negativos de las moléculas de agua son atraídos por los iones de sodio cargados con carga positiva.

Los diagramas de Amri, aunque no canónicos, constituyen dos representaciones microscópicas conceptuales sumamente separadas, abstractas y descontextualizadas de los procesos de disociación. La separación de las representaciones de lo que ocurre con el catión y el anión en dos ilustraciones discretas enfatiza el enfoque en la comunicación de una explicación conceptual. Ambas ilustraciones incluyen la representación de una red iónica para el nitrato de sodio, aunque de forma minimalista, muy esquemática y sin detalles, lo que puede reflejar la falta de conocimiento de los estudiantes sobre la naturaleza compleja de la red de nitrato de sodio. Cada uno de estos dos macrogrupos de diagramas representa tanto la composición como la actividad. La agregación por medio de la integración se produce en la representación visual de la composición y la actividad. La composición incluye la red y la representación del anión y el catión, así como la representación precisa de las moléculas de agua, con el uso de colores para distinguir mejor el hidrógeno y el oxígeno. En la representación de la actividad, las ilustraciones destacan la separación del catión y el anión del borde, y, en el diagrama de la izquierda, la representación detallada indica la actividad por medio de las líneas onduladas que implican el movimiento entre el catión y el extremo de oxígeno de la molécula de agua. En la infografía de Amri, la agregación también se produce a través de la acumulación, ya que los dos macrogrupos del diagrama aportan diferentes aspectos de composición y actividad en el fenómeno del enlace iónico.

El diagrama de Sim es un macrogrupo formado por cuatro ilustraciones conectadas por flechas. Aunque también representa una visión microscópica, la representación de los contenedores ofrece una contextualización más macroscópica. Las ilustraciones sí incluyen una composición y un intento de representar la actividad. Una limitación clave de la explicación de Sim es la omisión de la red iónica en el lenguaje verbal y de la imagen. La primera de las ilustraciones de Sim incluye una representación correcta de las moléculas de agua. En la segunda ilustración, intenta representar el nitrato de sodio de forma similar a la molécula de agua, en lugar de representarla como una red. En relación con la actividad, las líneas en la parte superior de la segunda ilustración parecen representar el nitrato de sodio que se introduce en el agua, lo que también es más bien una actividad macroscópica que microscópica. Aparte de esto, las flechas que representan la secuencia entre las ilustraciones dan cuenta de la intención de representar la actividad y existe claramente un cambio en lo que representa el nitrato de sodio y las moléculas de agua de las ilustraciones dos a la cuatro. La actividad que podría inferirse de la ilustración dos a la tres es que las moléculas de agua anteriormente representadas no parecen continuar intactas en la ilustración tres y parece haber algunos iones de nitrato desprendidos en la misma ilustración. Sin embargo, la naturaleza de la actividad representada no está clara debido a la inexactitud del significado de composición representado. La ilustración tres, por ejemplo, parece tener varias representaciones de lo que parece ser un átomo de oxígeno conectado a uno de hidrógeno. No está claro lo que las representaciones circulares azul y verde del cuarto diagrama representan. La representación de la actividad muestra la secuencia del experimento en lugar de centrarse en la actividad implicada en la disociación.

Los extensos y variados tipos de anotaciones en los diagramas de Amri se refieren tanto a la composición como a la actividad. Por lo tanto, la agregación se produce por medio de la integración mediante la representación de estos diferentes significados que construyen la tecnicalidad en el lenguaje verbal o en las imágenes, o en ambos. Los elementos clave representados se nombran o se indican con símbolos tales como $\mathrm{H}$ u O. Además, o bien la actividad se designa como una entidad de actividad (atracción), o bien la acción se describe como una figura (cláusula) como en 'el catión se separa de la red'. Esta última está colocada como una leyenda no numerada junto a la imagen de la izquierda. Debajo y a la izquierda de la imagen de la derecha, se encuentra una leyenda 
no numerada similar, 'el anión se separa de la red'. Las demás anotaciones están conectadas con los elementos de la imagen correspondientes mediante flechas. Por el contrario, Sim no utiliza casi ninguna anotación, salvo una anotación tipo leyenda subformulada de una sola frase: 'Los enlaces entre el $\mathrm{H} 2 \mathrm{O}$ y el $\mathrm{NaNo} 3$ se rompen creando enlaces entre sí' (la inexactitud de esta anotación delata la falta de comprensión de Sim de la disociación). Amri incluye algunos datos en el diagrama que no se mencionan en el texto principal, como la denominación del catión y el anión. El diagrama de Sim no proporciona información adicional. La posición de los diagramas en la respuesta de Amri en relación con los bloques de texto también muestra una alta cohesión. La frase final del bloque de texto superior, que indica la actividad de los dipolos de las moléculas de agua que separan los iones de la red, luego se elabora visual y verbalmente en los diagramas que se encuentran debajo de ella mediante el momenting o división por etapas, es decir, mostrando la subactividad constitutiva mediante un diagrama. La cohesión también se consigue en el bloque de texto inferior, ya que el comienzo de la primera frase condensa la explicación multimodal previa de forma sucinta como "El proceso anterior".

Al tratar de ofrecer una explicación del fenómeno descrito en la tarea de evaluación, Amri fue capaz de seleccionar con bastante amplitud y desplegar con eficacia las opciones multimodales de representación que caracterizan a las infografías. Amri hizo un uso más amplio de una variedad de tipos de anotación para construir tanto relaciones de composición como de actividad, mientras que Sim hizo un uso muy acotado de las anotaciones. En el despliegue de Amri de estos modos, la concordancia y complementariedad de la representación por medio de imágenes y el lenguaje verbal fue eficaz. En contraste, el diagrama de Sim solo mostraba la estructura de la molécula de agua y la secuencia del experimento, además de lo que aparecía en el texto. La coordinación de Amri de los diagramas anotados y los bloques de texto interpolados también fue altamente cohesionada. Amri fue capaz de desplegar con mayor eficacia los recursos del lenguaje verbal y de las imágenes para construir una representación clara y precisa, aunque evitando el desafío de incluir una representación detallada de la red iónica del nitrato de sodio. Aunque los aparentes conceptos erróneos de Sim sobre la naturaleza de la disociación y la falta de conocimientos sobre la red de nitrato de sodio son centrales en la insuficiencia de la respuesta, también está claro que el repertorio de recursos lingüísticos de este estudiante y los recursos para construir respuestas infográficas para contestar a las preguntas evaluativas son mucho más limitados que los de Amri.

\section{Discusión}

\section{Implicaciones para la investigación transdisciplinar de la semiótica}

\section{y la enseñanza de las ciencias}

Solo recientemente se ha dirigido la atención sobre la importancia de las imágenes multiestructurales en las ciencias (Doran, 2019; Martin, 2020), en las que dos o más de los significados ideacionales que construyen los fenómenos (composición, clasificación, actividad y propiedad) se representan con igual estatus en una sola visualización. La investigación que se presenta en este trabajo amplía este conocimiento para proponer un marco que describe las opciones de coarticulación de las imágenes y el lenguaje verbal, con el fin de construir combinaciones de diferentes tipos de significados en ensambles sinópticos imagen-lenguaje, condensados por medio de estrategias de acumulación e integración. Si bien estas visualizaciones que incorporan el lenguaje verbal dentro de representaciones centradas en imágenes son cada vez más características de los libros de texto de ciencias (Bezemer \& Kress, 2010; Bateman, 2008), los análisis multimodales anteriores de dichos textos de ciencias no han abordado cómo estas representaciones dan cuenta de los complejos de significado que implican la representación simultánea de dos o más de los diferentes tipos de campo de construcción de significado (Danielsson \& Selander, 2016; Knain, 2015; Peterson, 2016; Polias, 2015). 
Pocos estudios sobre las representaciones multimodales creadas por estudiantes han abordado la naturaleza y el alcance de la coarticulación de las imágenes y el lenguaje verbal, y en los casos en los que se ha abordado, la base semiótica para su estudio ha sido muy limitada. Por ejemplo, Gebre y Polman (2016) investigaron el grado en el que las infografías creadas por estudiantes de secundaria incluían significados representados por representaciones no textuales que no fuesen ya comunicadas por otras representaciones de este tipo, o por el lenguaje verbal. McDermott y Hand (2013, 2016) diseñaron una intervención para concientizar a los estudiantes sobre las formas de mejorar la integración de los modos no textuales en sus representaciones multimodales; sin embargo, en su escala para evaluar la integración no textual, cada uso de un modo no textual recibía un punto por cualquiera de las siguientes características: junto al texto, referido en el texto, incluye una leyenda, precisión científica, exhaustividad (cantidad de detalles) y originalidad (creado por el estudiante y no adoptado de otra fuente). Los tres primeros criterios solo son dispositivos para enlaces intermodales, pero no está claro si el texto se refiere al texto principal que acompaña a la representación multimodal, a bloques de texto interpolados como parte del ensamble multimodal, o a una anotación. No considera el modo en el que la combinación de imágenes y el lenguaje verbal construye los significados ideacionales relevantes para el tema, ni mucho menos la agregación de significados ideacionales que construyen un conocimiento complejo del campo. El uso del marco de coarticulación imagen-lenguaje en la agregación de significados en las respuestas infográficas esbozadas en este trabajo sugiere el potencial de ampliar los estudios transdisciplinarios en la semiótica educativa y la enseñanza de las ciencias. Esta transdisciplinariedad de las investigaciones sobre la creación de representaciones multimodales por parte de estudiantes en el aprendizaje de las ciencias podría proporcionar una mayor especificidad del uso de los recursos del lenguaje y la imagen por parte de los estudiantes y su coarticulación en la comunicación de la comprensión de los fenómenos complejos. De este modo, se mejora la capacidad de los resultados investigativos para informar a la pedagogía, lo que a su vez mejoraría la interpretación y creación de representaciones infográficas por parte de los estudiantes.

\section{Implicancias pedagógicas}

La interpretación crítica y la creación de infografías complejas que representen dos o más de las dimensiones del campo de construcción del significado ideacional (actividad, composición, clasificación y propiedad) mediante los recursos combinados de las imágenes y el lenguaje verbal son aspectos cruciales de la literacidad disciplinar multimodal de la ciencia que se les debe enseñar a los estudiantes de manera efectiva. Estos despliegues altamente sinópticos del conocimiento, cuando cuentan con apoyo de lectura por parte del docente, enseñanza explícita sobre cómo combinar los recursos visuales y del lenguaje para construir significado, y discusión crítica en el aula, pueden funcionar eficazmente para los estudiantes como agregaciones sumativas del conocimiento acumulado. Cuando no se produce una lectura de apoyo y una interacción en el aula que aborde de forma crítica la construcción multimodal de las infografías, la representación altamente condensada y a menudo implícita del significado en las infografías puede ser un obstáculo infranqueable para el aprendizaje, especialmente para los estudiantes de entornos socioeconómicos bajos o aquellos cuya primera lengua no corresponde con la lengua de enseñanza. Del mismo modo, el apoyo pedagógico explícito para los estudiantes que están aprendiendo a crear infografías se puede dar gracias a un docente que deconstruye, explica y compara críticamente múltiples infografías sobre el mismo tema; muestra la construcción de infografías y explica el despliegue de la imagen y del lenguaje verbal en conjunto; construye infografías con los estudiantes; permite la construcción colaborativa de infografías entre compañeros, y genera oportunidades para que los estudiantes hagan una construcción independiente con retroalimentación individual detallada. Todo esto puede permitir a los alumnos participar de manera efectiva en esta práctica de representación disciplinar y puede mejorar su rendimiento en los exámenes externos que requieren este tipo de respuestas a preguntas de respuesta breve. 
La atención explícita al desarrollo de la capacidad de los estudiantes para interpretar y crear representaciones infográficas de los fenómenos es más eficaz cuando se trata como una parte fundamental de la pedagogía de las ciencias, en lugar de cuando se le considera como un aprendizaje de la literacidad científica aislado de las experiencias de enseñanza y aprendizaje en el aula de ciencias. Este enfoque infundido del desarrollo de la literacidad disciplinar (Martin et al., en prensa; Unsworth et al., en prensa) propone un enfoque pedagógico que combina el fomento de la indagación del estudiante con el rol del docente de proporcionar orientación mediante la interacción en el contexto de la experiencia compartida (Martin \& Rose, 2005). En investigaciones posteriores, analizamos el rol facilitador de un metalenguaje accesible y compartido (incluyendo el metalenguaje derivado de la LSF), que describe las posibilidades de construcción de significados de los diferentes modos semióticos como apoyo de los docentes a los estudiantes para interpretar y crear diferentes niveles de representación que impliquen múltiples modos, para mostrar las relaciones casuales entre las estructuras cambiantes en actividades complejas (Unsworth et al., en prensa). Un modelo pedagógico eficaz para esto implica ciclos de enseñanza/aprendizaje (Martin et al., en prensa; Rose \& Martin, 2012). Estos ciclos se desarrollan en una serie de pasos: construcción del conocimiento de campo, lectura con apoyo docente, deconstrucción de textos de ejemplo y demostración de la creación de textos por parte del docente, construcción conjunta de textos por parte del docente y del estudiante y, finalmente, construcción independiente por parte del estudiante. Varias reconceptualizaciones de dicho ciclo han enfatizado que se puede entrar en diferentes fases, con diversos énfasis en la interpretación y en la producción, y con fases que se reciclan según las necesidades del grupo de estudiantes (Rose \& Martin, 2012; Unsworth, 2001). Estos enfoques infundidos multimodales de literacidad disciplinar se basan fundamentalmente en descripciones semióticas lingüísticas y visuales explícitas de los recursos de creación de significado de imagen y de lenguaje verbal. Dichas descripciones se basan a su vez en el marco analítico esbozado en este trabajo como apoyo al desarrollo pedagógico y no como un componente directo de la pedagogía. Se espera que los estudios semióticos emergentes sobre las infografías en las ciencias a nivel escolar y su relación con el aprendizaje y la enseñanza de las ciencias, tal y como se describe aquí, fomenten una mayor atención en la investigación y pedagogía al importante rol de las infografías en la enseñanza y el programa de estudio de las ciencias en la escuela secundaria.

Financiamiento: Esta investigación fue apoyada por una beca del Australian Research Council Linkage Projects (LP160100263) financiada por el Gobierno australiano. Las opiniones expresadas en este documento son las del autor y no necesariamente las del Consejo de Investigación australiano.

El artículo original fue recibido el 7 de enero de 2021

El artículo revisado fue recibido el 14 de abril de 2021

El artículo fue aceptado el 8 de junio de 2021

\section{Referencias}

Armstrong, Z., Deeker, W., Madden, A., McMahon, K., Naughton, K., Siwinski, S. \& Wheeler, A. S. (2019). Pearson Biology 12: New South Wales student book: Melbourne, Australia: Pearson Australia.

Bateman, J. (2008). Multimodality and Genre: A Foundation for Analysis. Londres, Inglaterra: Palgrave Macmillan.

Bennett, A. (2017). Pearson science. 9, T.C (2da ed.): Melbourne, Australia : Pearson Australia.

Bezemer, J. \& Kress, G. (2010). Changing Text: A Social Semiotic Analysis of Textbooks. Designs for Learning, 3(1/2), 10-29.

Borger, P. (2015). Nelson biology VCE units 1 \& 2 (3ra ed.): Melbourne, Australia: Nelson Cengage Learning.

Callow, J. (Ed.). (1999). Image matters: Visual texts in the classroom. Sydney, Australia: Primary English Teaching Association. 
Callow, J. (2013). The shape of text to come: How image and text work. Sidney, Australia: Primary English Teaching Association of Australia.

Chidrawi, G., Davis, A., Farr, R., Lampman, K., Matchett, B. \& Young, P. (2013). Nelson iscience 10. Melbourne, Australia: Nelson Cengage.

Danielsson, K. \& Selander, S. (2016). Reading Multimodal Texts for Learning-a model for cultivating multimodal literacy. Designs for Learning, 8(1), 25-36. https://doi.org/10.16993/dfl.72

de Silva Joyce, H. \& Gaudin, J. (2007). Interpreting the Visual: A Resource Book for Teachers. Sídney, Australia: Phoenix.

Doran, Y. J. (2017). The discourse of physics: Building knowledge through language, mathematics and image. Londres, Inglaterra: Routledge.

Doran, Y. J. (2019). Building knowledge through images in physics. Visual Communication, 18(2), 251-277. https://doi.org/10.1177/1470357218759825

Doran, Y. J. \& Martin, J. R. (2021). Field relations: Understanding scientific explanations. En K. Maton, J. R. Martin \& Y. J. Doran (Eds.), Teaching Science: Knowledge, Language, Pedagogy. Londres, Inglaterra: Routledge.

Gebre, E. H. \& Polman, J. L. (2016). Developing young adults' representational competence through infographicbased science news reporting. International Journal of Science Education, 38(18), 2667-2687. https://doi.org/10.1080/09500693.2016.1258129

Halliday, M. A. K. \& Martin, J. R., (Eds.). (1993). Writing science: Literacy and discursive power. Londres, Inglaterra: Falmer Press.

Höllerer, M. A., van Leeuwen, T., Jancsary, D., Meyer, R. E., Andersen, T. H. \& Vaara, E. (2019). Visual and multimodal research in organization and management studies. Routledge.

Huxley, L. \& Walter, M. (2019). Oxford Biology for Queensland Units 1 and 2. Melbourne, Australia: Oxford University Press.

Kinnear, J. (2016). Nature of biology. 1 : VCE units 1 and 2 (5a ed.): Milton, Australia: John Wiley \& Sons Australia Ltd.

Knain, E. (2015). Scientific literacy for participation: A systemic functional approach to analysis of school science discourses. Springer.

Kress, G. (2005). Gains and losses: New forms of texts, knowledge, and learning. Computers and composition, 22(1), 5-22. https://doi.org/10.1016/j.compcom.2004.12.004

Kress, G. \& van Leeuwen, T. (2006). Reading Images: The grammar of visual design (2a ed.). Londres, Inglaterra: Routledge.

Kress, G. \& van Leeuwen, T. (2021). Reading Images: The grammar of visual design (3a ed.). Londres, Inglaterra: Routledge.

Lemke, J. (1990). Talking science: Language, learning and values. Norwood, N.J.: Ablex.

Lemke, J. (2004). The literacies of science. En E. W. Saul (Ed.), Crossing borders in literacy and science instruction: Perspectives on theory and practice (pp. 33-47). Newark, D.E.: International Reading Association.

Linstead, G., Clarke, W., Devline, J., Madden, D., Rickard, H. C. \& Spenceley, M. (2012). Pearson science. 10 : S. B. Port Melbourne, Australia: Pearson Australia.

Lofts, G. \& Evergreen, M. J. (2015). Science quest 10: Australian curriculum (2a ed.): Milton, Australia: Jacaranda.

Martin, J. R. (2017). Revisiting field: Specialized knowledge in secondary school science and humanities discourse. Onomázein, 111-148. Recuperado de http://onomazein.letras.uc.cl/Articulos/N-SFL/SFL05-Martin.pdf

Martin, J. R. (2020). Revisiting field: Specialized knowledge in secondary school science and humanities discourse. En J. R. Martin, K. Maton \& Y. Doran (Eds.), Accessing Academic Discourse: Systemic Functional Linguistics and Legitimation Code Theory (pp. 114-148). Londres, Inglaterra: Routledge.

Martin, J. R. \& Rose, D. (2005). Designing Literacy Pedagogy: scaffolding asymmetries. En J. Webster, C. Matthiessen \& R. Hasan (Eds.), Continuing Discourse on Language (pp. 251-280). Londres, Inglaterra: Continuum.

Martin, J. R. \& Rose, D. (2012). Genre and texts: living in the real world. Indonesian Journal of Systemic Functional Linguistics, 1(1), 1-21.

Martin, J. R. \& Unsworth, L. (en preparación). Reading Images for Knowledge Building: Analyzing Infographics in School Science Londres, Inglaterra: Routledge. 
Martin, J. R., Unsworth, L. \& Rose, D. (en prensa). Condensing meaning: Imagic aggregations in secondary school science. En G. Parodi (Ed.), Multimodality: From corpus to cognition. Londres, Inglaterra: Bloomsbury.

Martin, J. R. \& Veel, R. (Eds.). (1998). Reading Science: Critical and functional perspectives on discourses of science. Londres, Inglaterra: Routledge.

McDermott, M. A. \& Hand, B. (2013). The impact of embedding multiple modes of representation within writing tasks on high school students' chemistry understanding. Instructional Science, 41(1), 217-246. https://doi.org/10.1007/s11251-012-9225-6

McDermott, M. A. \& Hand, B. (2016). Modeling scientific communication with multimodal writing tasks: Impact on students at different grade levels. En B. Hand, M. McDermott \& V. Prain (Eds.), Using multimodal representations to support learning in the science classroom (pp. 183-211). Cham, Suiza: Springer.

Nunes, T., Bryant, P., Strand, S., Hillier, J., Barros, R. \& Miller-Friedmann, J. (2017). Review of SES and science learning in formal educational settings. Londres, Inglaterra: University of Oxford/Education Endowment Foundation.

Ozdamli, F. \& Ozdal, H. (2018). Developing an instructional design for the design of infographics and the evaluation of infographic usage in teaching based on teacher and student opinions. EURASIA Journal of Mathematics, Science and Technology Education, 14(4), 1197-1219. https://doi.org/10.29333/ejmste/81868

Painter, C., Martin, J. R. \& Unsworth, L. (2013). Reading Visual Narratives: Image Analysis of Children's Picture Books. Londres, Inglaterra: Equinox.

Peterson, M. O. (2016). Schemes for Integrating Text and Image in the Science Textbook: Effects on Comprehension and Situational Interest. International Journal of Environmental and Science Education, 11(6), 1365-1385.

Polias, J. (2015). Apprenticing students into science: Doing, talking, writing and drawing scientifically. Estocolmo, Suecia: Hallgren \& Fallgren.

Polman, J. L. \& Gebre, E. H. (2015). Towards critical appraisal of infographics as scientific inscriptions. Journal of Research in Science Teaching, 52(6), 868-893. https://doi.org/10.1002/tea.21225

Rickard, G. (2017). Pearson Science 9. Melbourne, Pearson.(p.108)

Rose, D. \& Martin, J. R., (2012). Learning to write, reading to learn: Genre, knowledge and pedagogy across the curriculum. Londres, Inglaterra: Equinox.

Silvester, H. (2016). Oxford science 10 : Victorian curriculum. Melbourne, Australia: Melbourne Oxford University Press Australia.

Teese, R. (2013). Academic Success and Social Power: Examinations and Inequality. Melbourne, Australia: Australian Scholarly Publishing.

Tytler, R., Prain, V. \& Hubber, P. (2018). Representation Construction as a Core Science Disciplinary Literacy. En K.-S. Tang \& K. Danielsson (Eds.), Global Developments in Literacy Research for Science Education (pp. 301-318). Cham, Suecia: Springer.

Unsworth, L. (2001). Teaching Multiliteracies Across the Curriculum: Changing contexts of text and image in classroom practice. Buckingham, United Kingdom: Open University Press.

Unsworth, L. (2020). Intermodal relations, mass and presence in school science explanation genres. En Michele Zappavigna \& S. Dreyfus (Eds.), Discourses of hope and reconciliation: J. R. Martin's contributions to Systemic Functional Linguistics (pp. 131-152). Londres, Inglaterra: Bloomsbury Academic.

Unsworth, L. \& Cleirigh, C. (2009a). Multimodality and reading: The Construction of meaning through imagetext interaction. En C. Jewitt (Ed.), Handbook of Multimodal Analysis (pp. 151-164). Londres, Inglaterra: Routledge.

Unsworth, L. \& Cleirigh, C. (2009b). Towards a relational grammar of image-verbiage synergy: Intermodal representations. En S. Dreyfus, S. Hood \& M. Stenglin (Eds.), Semiotic Margins. University of Sydney: Australian Systemic Functional Linguistics Association (www.asfla.org.au).

Unsworth, L., Tytler, R., Fenwick, L., Humphrey, S., Chandler, P., Herrington, M. \& Pham, L. (in press). Multimodal Literacy in School Science: Transdisciplinary Perspectives on Theory, Research and Pedagogy: Routledge.

Walsh, E. M. \& McGowan, V. C. (2017). 'Let your data tell a story:'climate change experts and students navigating disciplinary argumentation in the classroom. International Journal of Science Education, 39(1), 20-43. https://doi.org/10.1080/09500693.2016.1264033 